\title{
Production of Red Pigment by Monascus purpureus Nrrl 1992 under Submerged and Solid-state Fermentation
}

\author{
Shaimaa A. Mousa ${ }^{(1,2) \#}$, Dalia A.M. Abdou ${ }^{(1)}$, Gamal A. Mohamed ${ }^{(2)}$, Mohamed A. \\ Abo-El-Seoud (2), Al-Zahraa A. Karam Eldin ${ }^{(1)}$ and Adel A. El-mehalawy(1) \\ (1)Department of Microbiology, Faculty of Science, Ain Shams University, Cairo, \\ Egypt; (2) Plant Research Department, Nuclear Research Center, Atomic Energy \\ Authority, Cairo, Egypt.
}

\begin{abstract}
WING to its broad industrial applications, the present study was directed to study the production of red pigment by Monascus purpureus under submerged and solid state fermentations. The effect of gamma radiation on pigment production was studied. The antifungal activity of red pigment was evaluated against some plant pathogens. The results show that maximum yield of pigment was achieved with fermentation conducted on modified Lin's (ML) broth medium at $30^{\circ} \mathrm{C}$ and $\mathrm{pH} 7$ for 16 days. Maltose $(50 \mathrm{~g} / \mathrm{L})$ and peptone $(2.5 \mathrm{~g} / \mathrm{L})$ were found the most suitable carbon and nitrogen sources for maximum pigment production. In solid state fermentation, maximum pigment yield was achieved using potato peel as a solid substrate optimized by using ML broth as a moistening agent at $75 \%$ moisture content and incubated for 16 days. Gamma radiation at $1 \mathrm{KGy}$ was found to be the most effective dose of those tested for maximum pigment production. The antifungal activity of pigment indicated activity against Aspergillus niger, Aspergillus flavus and Alternaria sp. Besides, there was no activity against Fusarium solani and Penicillium sp.
\end{abstract}

Keywords: Red pigment, Submerged fermentation, Solid-state Fermentation, Monascus purpureus.

\section{Introduction}

Microbial pigments provide a possible alternative to chemically synthetic pigments such as synthetic food colors, some of which impose a risk to human health and may be carcinogenic (Blanc et al., 1995). Addition of color to processed food is an old practice, however, production of pigments from microbes is a more recent phenomenon. Microbial genera used as a source of natural pigments are Monascus, Khodotorula, Bacillus, Achromobacter, Rhodosporium and Streptomyces sp. (Panesar et al., 2015). There is a growing interest in production of microbial pigments due to their natural characters providing potential for safe uses including medicinal properties, nutritional effects and controllable and predictable yield (Joshi et al., 2003).

Monascus purpureus is one of the most potent producers of pigments. Monascus sp. produces a complex mixture of six chemically defined colored compounds of polyketide origin (Campoy et al., 2006). These compounds are rubropunctatine, monascorubrine (orange), rubropunctamine, monascorubramine (red), monascine and ankaflavine (yellow) (Zhou et al., 2009). The red pigment is of high demand, especially for its use in meat products to substitute for nitrites (Fabre et al., 1993). Lin et al. (2008) reported that Monascus pigments have potent therapeutic use. Kumar et al. (2012) proved that red pigments showed antibacterial activity against Bacillus subtilis, Bacillus megaterium, Escherichia coli and Pseudomonas aeriginosa. Thus the pigment of Monascus purpureus has a preservative value. They further attributed this activity to the presence of monascidin A.

\section{Materials and Methods}

Fungal strain

Monascus purpureus (NRRL 1992) ATCC16436 was obtained from Microbiological Resources Centre (Cairo MIRCEN), Faculty of Agriculture, Ain Shams University, Egypt. The strain was maintained on Malt extract (ME) agar and incubated at $30^{\circ} \mathrm{C}$ for 7 days, preserved at $4^{\circ} \mathrm{C}$, and sub-cultured once every 4 weeks. 
Production of red pigment by M. purpureus under submerged fermentation

One plug of the freshly prepared culture (7 days old from ME agar plates) was introduced aseptically into a $100 \mathrm{ml}$ Erlenmeyer flask containing $50 \mathrm{ml}$ broth medium ( $\mathrm{pH} 5.0$ ) and fermentation was carried out statically at $30^{\circ} \mathrm{C}$ for 20 days in darkness (Lee et al., 2001).

\section{Effect of different fermentation media on pigment production}

This procedure was carried out according to Lee et al. (2001), Atlas (2004), Dikshit \& Tallapragada (2011), Rashmi \& Padmavathi (2013) and Tallapragada et al. (2013).

\section{Effect of temperature on pigment production}

To study the effect of temperature on mycelia growth and pigment production modified Lin's (ML) medium was inoculated with $M$. purpureus and incubated at different temperature viz. $20^{\circ} \mathrm{C}$ to $40^{\circ} \mathrm{C}$ for 20 days in static conditions.

Effect of different fermentation periods on pigment production

Biomass and pigment yield were estimated every 2 days after inoculation, fermentation periods range were 2 to 20 days.

\section{Effect of different pH on pigment production}

The effect of $\mathrm{pH}$ on mycelia growth and pigment production was studied by using $\mathrm{pH}$ values 4.0 to 9.0 .

Effect of different carbon sources on pigment production

Glucose, maltose, galactose, lactose, sucrose and starch were tested both qualitatively and quantitatively for pigment production. All were used at a concentration of $20 \mathrm{~g} / \mathrm{L}$, the same as that of glucose in the original ML medium.

\section{Effect of different nitrogen sources on pigment production}

Monosodium glutamate, malt extract, peptone, yeast extract, and sodium nitrate were tested both qualitatively and quantitatively for pigment production. All were used at a concentration of $1.5 \mathrm{~g} / \mathrm{L}$, the same as that of MSG in the original ML medium.

Effect of different mineral salts on pigment production

Four different mineral salts were added individually to the medium as substitutes for ferrous sulphate. These minerals were manganese sulphate, zinc sulphate and copper sulphate. All were used at a concentration of $0.14 \mathrm{~g} / \mathrm{L}$.

Production of red pigment by M. purpureus under solid-state fermentation conditions

Rice, rice straw, rice bran, wheat straw, wheat bran, corn cob, potato peel and sugarcane bagasse were used as solid substrates for testing the ability of the fungal strain to produce red pigment. Five grams of each substrate was added in a $100 \mathrm{ml}$ conical flask and tap water was used. The substrates-based media were inoculated and incubated at $30^{\circ} \mathrm{C}$ for 23 days in static conditions. Moisture content was maintained at $65 \%$ (Patcharee et al., 2007).

Effect of different incubation periods on pigment production

Production of red pigment by Monascus purpureus was investigated in potato peel, the best solid substrate for red pigment production. Sterilized flasks were cooled, inoculated and incubated at $30^{\circ} \mathrm{C}$ in static condition. Pigment was estimated 4, 8, 12, 16, 20, 23, 26 and 29 days after inoculation.

Effect of different moisture content on pigment production

A range of $45,55,65,75$ and $85 \%$ moisture content was prepared (Patcharee et al., 2007).

Effect of different moistening agents on pigment production

The tested moistening agents were tap water, distilled water, mineral salt solution and optimized ML broth.

\section{Effect of gamma irradiation}

Spore suspensions $\left(1.0 \times 10^{6}\right.$ spores $\left./ \mathrm{ml}\right)$ of fungal spore were irradiated by gamma rays at different doses as follows: $0.25,0.50,0.75,1.00$, $1.25,1.50,1.75$ and $2.00 \mathrm{KGy}$. The irradiated spore suspensions were kept in darkness overnight at $4^{\circ} \mathrm{C}$ to avoid photo-reactivation. Aliquots of $5 \mathrm{~g}$ of the sterilized potato peel moistened by optimized broth ( $75 \%$ moisture content) in $100 \mathrm{ml}$ Erlenmeyer flasks were inoculated with $1 \mathrm{ml}$ of the gamma irradiated spores. The flasks were kept at $30^{\circ} \mathrm{C}$ for 16 days.

\section{Gamma source specifications}

The process of irradiation was carried out at 
the Nuclear Research Center, Atomic Energy Authority, Inshas, Egypt. The facility used was a ${ }^{60} \mathrm{Co}$ gamma chamber, MC20, Russia. Irradiation was performed using ${ }^{60} \mathrm{Co}$ gamma rays at a dose rate of $0.99 \mathrm{KGy} / \mathrm{h}$ at the time of the experiment.

Anti-fungal activity of extracted red pigment

Pathogenic fungal strains were isolated from different infected plants. These strains were Aspergillus niger, isolated from onion bulb causing black rot disease (Sharma, 2012), Aspergillus flavus, isolated from corn causing ear rot disease in cereal grains (Ramirez-Camejo et al., 2012), Alternaria sp., isolated from tomato causing early blight disease (Chaerani \& Voorrips, 2006), Fusarium solani, isolated from rotted tuber of potato causing soft rot disease (Leslie et al., 2006) and Penicillium sp., isolated from rotted lemon causing soft rot disease (Louw \& Korsten, 2015).

The isolation was carried out in a Microbiology laboratory, Nuclear Research Center at Atomic Energy Authority and identification based on morphological characters was made according to Nelson et al. (1983). Antifungal evaluation was carried out using an agar well diffusion assay technique (Bennett et al., 1996). Different dilutions of red pigment of irradiated and nonirradiated Monascus $(0,5,10,50 \mu \mathrm{g} / \mathrm{ml})$ applied in the agar well.

\section{Analytical methods}

\section{Estimation of dry cell weight}

The mycelia separated from broth by filtration through Whatman No. 1 filter papers were weighed on an analytical scale, vacuum filtered through preweighed membrane filters, washed with distilled water, dried in an oven at $50^{\circ} \mathrm{C}$ for $24 \mathrm{~h}$ tell constant weight then weighed (Mukherjee \& Singh, 2011).
Pigment extraction and estimation from liquid cultures

This procedure was carried out according to Carvalho et al. (2003). Pigment yield was expressed as $\mathrm{O} . \mathrm{D} / \mathrm{ml}$ filtrate after recording the specific absorbance at 510nm (Prajapati et al., 2014).

Pigment extraction and estimation from solid cultures

Pigment was extracted according to the method described by Babitha et al. (2007). Pigment yield was expressed as O.D/g dry substrate after recording the specific absorbance at 510nm (Rajeswari et al., 2014).

\section{Statistical analyses}

Results were expressed as the mean \pm standard deviation (SD). Statistical significance was evaluated using analysis of variance (ANOVA, SPSS software version 22) test followed by the least significant difference (LSD) test at 0.05 level.

\section{$\underline{\text { Results }}$}

Selection of the proper fermentation broth medium

Six types of fermentation media were screened to select the broth medium optimal for red pigment production by Monascus purpureus. Modified Lin's medium was found to be the best broth for production of red pigment, wherein maximum pigment reached $(0.277 \pm 0.0110 . \mathrm{D} /$ $\mathrm{ml})$. However, maximum fungal growth $(5.96 \pm$ $0.45 \mathrm{~g} / \mathrm{L})$ was observed using ME broth. PD broth was found to be a good broth medium for pigment production $(0.225 \pm 0.017 \mathrm{O} . \mathrm{D} / \mathrm{ml})$ (Table 1$)$. The results also indicated that $\mathrm{CP}$ broth was unsuitable for pigment production.

TABLE 1. Effect of different broth media on growth (g/L culture filtrate) and pigment yield (O.D/ml culture filtrate) of Monascus purpureus.

\begin{tabular}{lcc}
\hline Broth medium & Pigment yield $(\mathbf{O} . \mathbf{D} / \mathbf{m l})$ & Dry cell weight $(\mathrm{g} / \mathbf{L})$ \\
\hline 1. ML & $0.277 \pm 0.011^{\mathrm{a}}$ & $4.54 \pm 0.38^{\mathrm{b}}$ \\
2. PD & $0.225 \pm 0.017^{\mathrm{b}}$ & $4.62 \pm 0.23^{\mathrm{b}}$ \\
3. ME & $0.129 \pm 0.012^{\text {cd }}$ & $5.96 \pm 0.45^{\mathrm{a}}$ \\
4. SG & $0.139 \pm 0.006^{\mathrm{c}}$ & $5.70 \pm 0.13^{\mathrm{a}}$ \\
5. YES & $0.115 \pm 0.004^{\mathrm{de}}$ & $3.39 \pm 0.06^{\mathrm{c}}$ \\
6. CP & $0.102 \pm 0.003^{\mathrm{e}}$ & $3.90 \pm 0.01^{\mathrm{c}}$ \\
\hline
\end{tabular}

(ML) Modified Lin's medium (Lee et al., 2001), (PD) Potato Dextrose medium (Dikshit \& Tallapragada, 2011), (ME) Malt Extract medium (Rashmi \& Padmavathi, 2013), (SG) Synthetic growth medium (Tallapragada et al., 2013), (YES) Yeast extract Sucrose (Atlas, 2004), (CP) Chaterjee production medium (Chatterjee et al., 2009). 
Effect of physical fermentation conditions on pigment production

Production of red pigment by the tested fungal strain was found to be greatly affected by the physical fermentation conditions used (Fig. 1). Results of incubation temperature (Fig. 1a) revealed that by increasing the temperature both fungal growth and pigment production increased till maximum values at $30^{\circ} \mathrm{C}$ after which a decline in both levels were observed $\left(35-40^{\circ} \mathrm{C}\right)$.

Regarding incubation time, maximum values of both fungal growth and pigment production was increased by increasing the incubation periods till 16 days after which both growth and pigment production decreased (Fig. 1b). Data in Fig. 1c showed that, by increasing $\mathrm{pH}$ values, both growth and pigment production were increased till reached the maximum at $\mathrm{pH} 7$, after which any increase in $\mathrm{pH}$ value was accompanied by a decrease in both growth and pigment production.

\section{Effect of carbon sources}

It is revealed from data (Table 2) that for growth of Monascus, glucose $(20 \mathrm{~g} / \mathrm{L})$ is the best of the carbon sources tested $(4.27 \pm 0.07 \mathrm{~g} / \mathrm{L})$, while for pigment production maltose is the best carbon source $(0.345 \pm 0.003 \mathrm{O} . \mathrm{D} / \mathrm{ml})$. No significant difference in growth was found in using maltose and galactose $(3.37 \pm 0.13,3.20 \pm$ $0.18 \mathrm{~g} / \mathrm{L})$, respectively. Results of testing different concentrations of maltose (Fig. 2a) showed that $50 \mathrm{~g} / \mathrm{L}$ maltose was the best concentration for maximum pigment production.

\section{Effect of nitrogen sources:}

Data in Table 2 indicated that peptone was the optimal nitrogen source among those tested, where the highest level of pigment was obtained $(0.378 \pm 0.015$ O.D $/ \mathrm{mL})$. However, MSG was the most favorable nitrogen source for fungal growth. The tested nitrogen sources could be arranged for their suitability for pigment production in the following order: peptone $>$ monosodium glutamate $>$ yeast extract $>$ sodium nitrate $>$ malt extract. Results of testing different concentrations of peptone (Fig. 2b) showed that $2.5 \mathrm{~g} / \mathrm{L}$ peptone was the best concentration for maximum pigment production.

\section{Effect of different minerals}

It is shown from data of Table 3 that $\mathrm{Fe}$ mineral salt was the best for maximum pigment production $(0.492 \pm 0.002$ O.D/mL). However,
$\mathrm{Zn}$ mineral was the most favorable for fungal growth. $\mathrm{Cu}$ mineral salt was also a good mineral for pigment production.
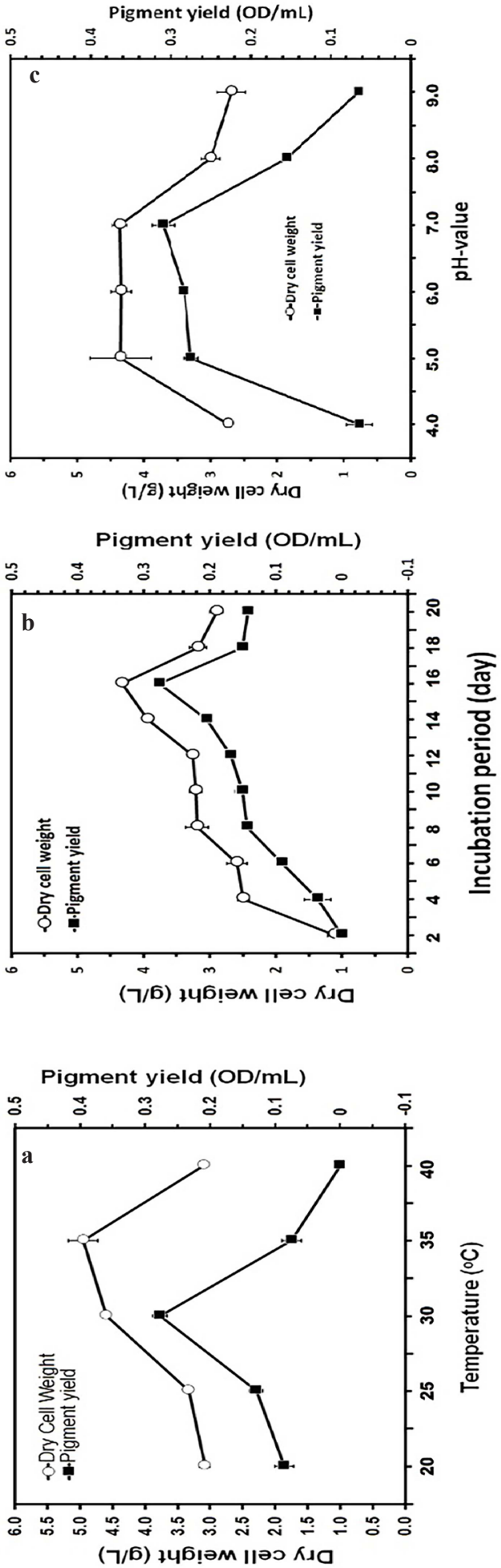

Fig. 1. Effect of different physical conditions on growth $(\mathrm{g} / \mathrm{L}$ cultural filtrate) and pigment yield $(\mathrm{O} . \mathrm{D} / \mathrm{ml}$ cultural filtrate) of Monascus purpureus. 
TABLE 2. Effect of different carbon and nitrogen sources on growth (g/L culture filtrate) and pigment yield (O.D/ ml culture filtrate) of Monascus purpureus.

\begin{tabular}{lcc}
\hline Carbon and nitrogen sources & Pigment yield $(\mathbf{O} . \mathbf{D} / \mathbf{m L})$ & Dry cell weight $(\mathbf{g} / \mathbf{L})$ \\
\hline Glucose $(\mathrm{C})$ & $0.307 \pm 0.002^{\mathrm{b}}$ & $4.27 \pm 0.07^{\mathrm{a}}$ \\
Maltose & $0.345 \pm 0.003^{\mathrm{a}}$ & $3.37 \pm 0.13^{\mathrm{b}}$ \\
Galactose & $0.301 \pm 0.002^{\mathrm{b}}$ & $3.20 \pm 0.18^{\mathrm{b}}$ \\
Lactose & $0.182 \pm 0.001^{\mathrm{d}}$ & $2.74 \pm 0.04^{\mathrm{c}}$ \\
Sucrose & $0.064 \pm 0.011^{\mathrm{e}}$ & $2.92 \pm 0.02^{\mathrm{c}}$ \\
Starch & $0.224 \pm 0.005^{\mathrm{c}}$ & $2.25 \pm 0.11^{\mathrm{d}}$ \\
Malt extract & $0.137 \pm 0.007^{\mathrm{d}}$ & $4.85 \pm 0.01^{\mathrm{ab}}$ \\
Sodium nitrate & $0.139 \pm 0.005^{\mathrm{d}}$ & $4.60 \pm 0.40^{\mathrm{b}}$ \\
Yeast extract & $0.339 \pm 0.003^{\mathrm{c}}$ & $4.00 \pm 0.02^{\mathrm{c}}$ \\
Monosodium glutamate $(\mathrm{C})$ & $0.355 \pm 0.003^{\mathrm{b}}$ & $5.03 \pm 0.11^{\mathrm{a}}$ \\
Peptone & $0.378 \pm 0.015^{\mathrm{a}}$ & $4.08 \pm 0.04^{\mathrm{c}}$ \\
\hline
\end{tabular}
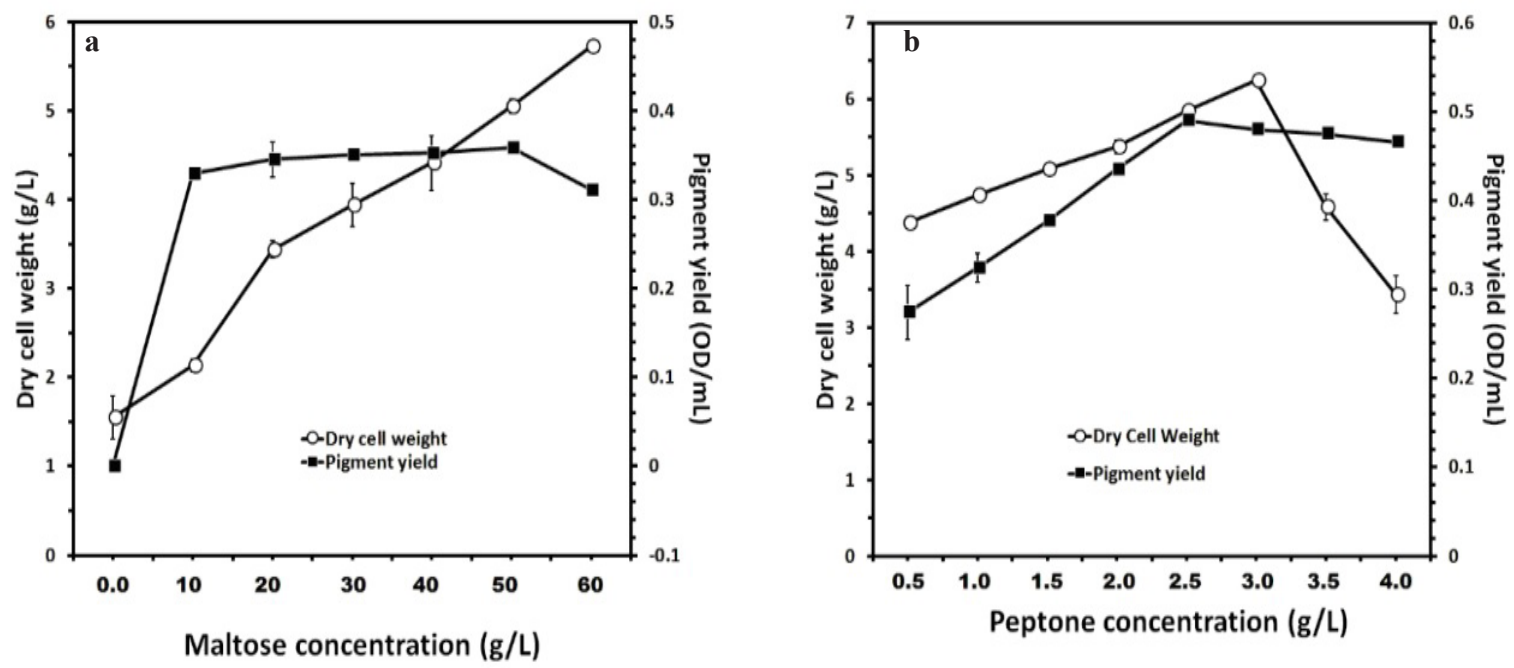

Fig. 2. Effect of different concentrations of maltose and peptone on growth (g/L culture filtrate) and pigment yield (O.D/ml culture filtrate) of Monascus purpureus.

TABLE 3. Effect of different minerals salts on growth (g/L culture filtrate) and pigment yield (O.D/ml culture filtrate) of Monascus purpureus.

\begin{tabular}{lcc}
\hline Minerals salt & Pigment yield $(\mathbf{O} . \mathbf{D} / \mathbf{m L})$ & Dry cell weight $(\mathbf{g} / \mathbf{L})$ \\
\hline $\mathrm{Zn}$ & $0.211 \pm 0.005^{\mathrm{c}}$ & $6.86 \pm 0.40^{\mathrm{a}}$ \\
$\mathrm{Mn}$ & $0.191 \pm 0.005^{\mathrm{d}}$ & $6.34 \pm 0.07^{\mathrm{b}}$ \\
$\mathrm{Cu}$ & $0.418 \pm 0.013^{\mathrm{b}}$ & $4.57 \pm 0.09^{\mathrm{d}}$ \\
$\mathrm{Fe}(\mathrm{C})$ & $0.492 \pm 0.002^{\mathrm{a}}$ & $5.45 \pm 0.09^{\mathrm{c}}$ \\
\hline
\end{tabular}

Suitability of different solid substrates for pigment production

It is shown from Table 4 that of the eight substrates used, rice was the most suitable solid substrate for pigment production by the fungal strain $(3.627 \pm 0.03 \mathrm{O} . \mathrm{D} / \mathrm{g}$ dry substrate). Potato peel proved to be a good substrate for pigment production, where a yield $(2.636 \pm 0.04 \mathrm{O} . \mathrm{D} / \mathrm{g}$ dry substrate) was obtained. Wheat straw proved to be unfavorable for pigment production. Although rice gave the highest pigment yield, potato peel as a cheap substrate was selected to complete the subsequent experimental series. 
TABLE 4. Effect of different substrates on pigment yield (O.D/g dry substrate) by solid fermentation grown culture of Monascus purpureus.

\begin{tabular}{lc}
\hline $\begin{array}{l}\text { Natural } \\
\text { substrate }\end{array}$ & $\begin{array}{c}\text { Pigment yield } \\
\text { (O.D/g dry substrate) }\end{array}$ \\
\hline Rice & $3.627 \pm 0.03^{\mathrm{a}}$ \\
Rice straw & $0.257 \pm 0.02^{\mathrm{d}}$ \\
Rice bran & $1.30 \pm 0.03^{\mathrm{c}}$ \\
Corn cob & $0.128 \pm 0.02^{\mathrm{de}}$ \\
Potato peel & $2.636 \pm 0.04^{\mathrm{b}}$ \\
Sugarcane & $0.210 \pm 0.06^{\mathrm{de}}$ \\
bagasse & $0.00^{\mathrm{e}}$ \\
Wheat straw & $1.193 \pm 0.02^{\mathrm{c}}$ \\
\hline
\end{tabular}

Effect of incubation periods and moisture content

Data in Fig. 3 show the effect of incubation periods and moisture content on pigment production by the fungal strain. Maximum pigment yield was observed after 16 days of incubation (3.09 \pm 0.04 O.D/ml) (Fig. 3a). After which any increase in the incubation period was accompanied by a decrease in pigment levels. Figure $3 \mathrm{~b}$ indicated that by increasing moisture content there is a gradual increase in red pigment production till a maximum value at $75 \%$ moisture content $(3.86 \pm 0.07)$, then a decline was obtained on increasing the moisture content to $85 \%$.

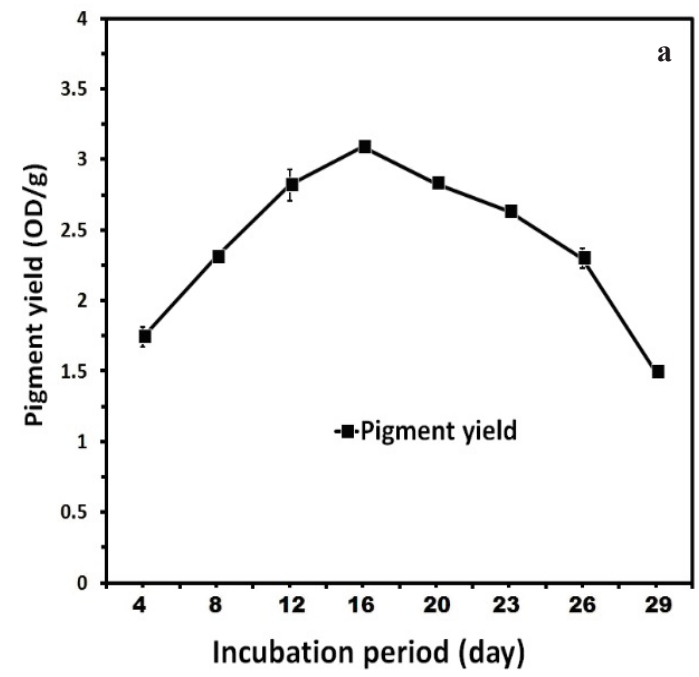

Effect of moistening agents

Data in Table 5 indicated that on using the optimized broth as a moistening agent, maximum pigment yield was achieved $(6.08 \pm 0.04$ O.D/g dry substrate). All tested moistening agents gave higher production of pigment yield except for distilled water as compared with control (tap water).

\section{Effect of gamma irradiation}

The effect of gamma irradiation on pigment production is shown in Fig. 4. By receiving higher irradiation doses, a reduction in pigment production was detected. The results also indicated that at $1 \mathrm{KGy}$ the production of red pigment reached its maximum value compared to non-irradiated fungal spores $(9.4 \pm 0.1 \mathrm{O} . \mathrm{D} / \mathrm{g}$ and $6.02 \pm 0.02 \mathrm{O} . \mathrm{D} /$ $\mathrm{ml}$, respectively) by increasing percentage of $64 \%$. Increasing the irradiation dose was accompanied by a decrease in pigment production till $2.00 \mathrm{KGy}$ at which no pigment was produced.

\section{Antifungal activity of extracted red pigment}

Data in Table 6 show that the prepared red pigment extracts (either from irradiated cultures or from non-irradiated cultures) has antifungal activity against all the tested fungal species except for Penicillium sp. and Fusarium solani. The results clearly indicate an estimated MIC for A. niger and A. flavus was $10 \mu \mathrm{g} / \mathrm{ml}$, however it was $50 \mu \mathrm{g} / \mathrm{ml}$ for Alternaria sp. The obtained results also showed that there was no increased activity of using both extracts at a concentration of $5 \mu \mathrm{g} / \mathrm{ml}$.

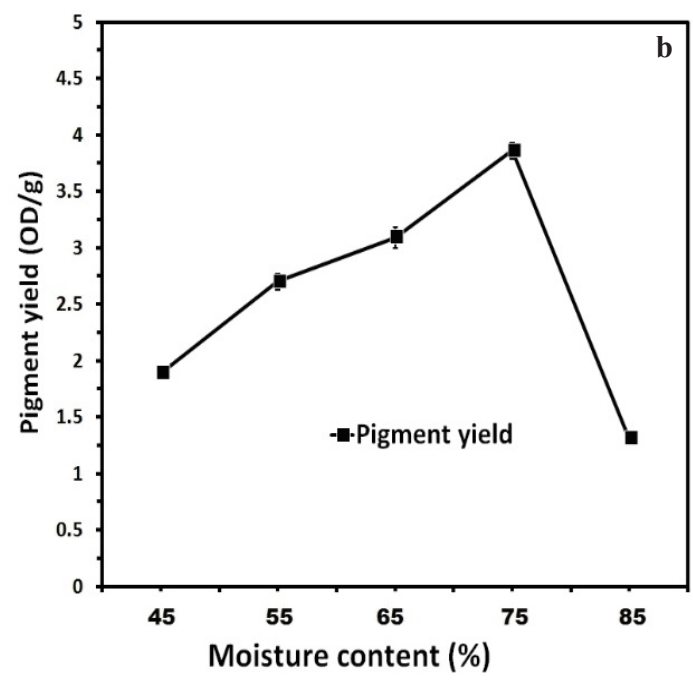

Fig.3. Effect of different incubation periods and moisture content on pigment yield (O.D/g dry substrate) of Monascus purpureus grown on potato peel. 
TABLE 5. Effect of different moistening agents on pigment yield (O.D/g dry substrate) of Monascus purpureus grown on potato peel.

\section{Moistening agent Pigment yield (O.D/g)}

Tap water (C)

$3.07 \pm 0.06^{\mathrm{c}}$

Distilled water

$2.51 \pm 0.05^{\mathrm{d}}$

Minerals salt solution

$4.82 \pm 0.08^{\mathrm{b}}$

Optimized broth

$6.08 \pm 0.04^{\mathrm{a}}$

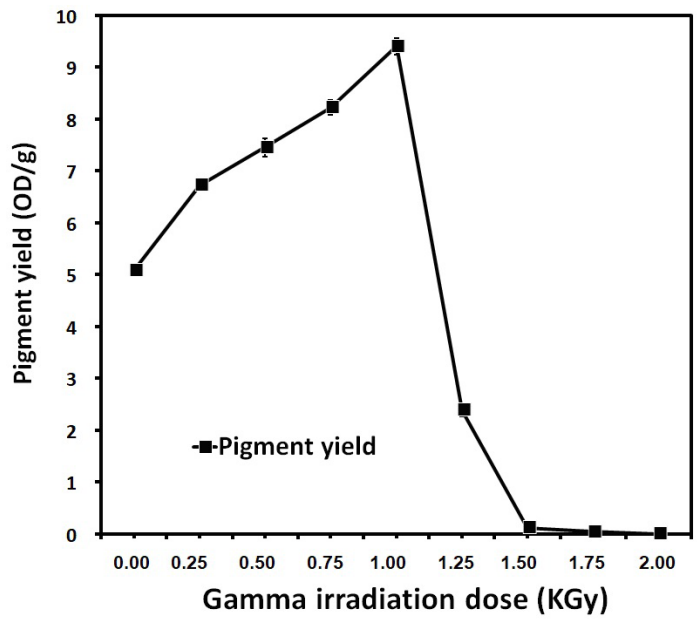

Fig. 4. Effect of different radiation doses on pigment yield (O.D/g dry substrate) of Monascus purpureus grown on potato peel.

TABLE 6. Effect of different concentrations of red pigment $(\mu \mathrm{g} / \mathrm{ml})$ against some plant pathogenic fungi.

\begin{tabular}{|c|c|c|c|c|c|c|}
\hline \multirow{4}{*}{ Organism } & \multicolumn{6}{|c|}{ Diameter of inhibition zone (cm) } \\
\hline & \multicolumn{3}{|c|}{ Non-irradiated culture } & \multicolumn{3}{|c|}{ Irradiated culture } \\
\hline & \multicolumn{3}{|c|}{ Concentration $\mu \mathrm{g} / \mathrm{ml}$} & \multicolumn{3}{|c|}{ Concentration $\mu \mathrm{g} / \mathrm{ml}$} \\
\hline & $5 \mu \mathrm{g} / \mathrm{ml}$ & $10 \mu \mathrm{g} / \mathrm{ml}$ & $50 \mu \mathrm{g} / \mathrm{ml}$ & $5 \mu \mathrm{g} / \mathrm{ml}$ & $10 \mu \mathrm{g} / \mathrm{ml}$ & $50 \mu \mathrm{g} / \mathrm{ml}$ \\
\hline Aspergillus flavus & - & $5.03 \pm 0.05$ & $5.4 \pm 0.05$ & - & $5 \pm 0.10$ & $5.4 \pm 0.11$ \\
\hline Aspergillus niger & - & $3.5 \pm 0.25$ & $4.03 \pm 0.05$ & - & $3.3 \pm 0.26$ & $3.9 \pm 0.05$ \\
\hline Alternaria $s p$. & - & - & $3.3 \pm 0.15$ & - & - & $3.4 \pm 0.15$ \\
\hline Fusarium solani & - & - & - & - & - & - \\
\hline Penicillium sp. & - & - & - & - & - & - \\
\hline
\end{tabular}

\section{Discussion}

The ability of $M$. purpureus ATCC16436 (NRRL1992) to produce red pigment was evaluated on six different types of fermentation broth media. Modified Lin's broth medium was found the most suitable fermentation broth that supported the highest pigment production by the experimental fungal strain. In agreement with our results, Lee et al. (2001) used the same broth medium for maximum red pigment production by M. purpureus ATCC16365. The obtained results further indicated that PD broth was a good medium for the production of red pigment by the fungal strain. Dikshit \& Tallapragada (2011) used PD broth for pigment production by $M$. sanguineus. Kumar et al. (2012) used PD broth for pigment production by $M$. purpureus MTCC410. Prajapati et al. (2014) used YM (Yeast and Malt) broth for pigment production by M. purpureus MTCC410.

In the current study, incubation temperature was confirmed to play a critical role in production of red pigment by the experimental fungal strain. Maximum pigment production by the fungal strain was achieved at incubation temperature of $30^{\circ} \mathrm{C}$. In the same connection, production of red pigment was performed at the same temperature by many authors (Dikshit \& Tallapragada, 2012; Kumar et al., 2012; Prajapati et al., 2014; Rajeswari et al., 2014 and Singh et al., 2015). Maximum pigment production was recorded after 16 days of incubation. In agreement with these results Dikshit \& Tallapragada (2012) used the 
same incubation time for pigment production by $M$. sanguineus and $M$. purpureus MTCC410. Also, Tallapragada et al. (2013) used the same incubation time for maximum pigment production by two Monascus sp. namely $M$. purpureus and M. sanguineus.

The best $\mathrm{pH}$ value that supported maximum pigment production was 7.0. In partial agreement with these results, Dikshit \& Tallapragada (2012) and Lee et al. (2001) used pH of 6.5 for pigment production. Silveira et al. (2008) used $\mathrm{pH}$ of 6.5 for pigment production by $M$. purpureus NRRL1992. Hamdi et al. (1996) concluded that red pigment synthesis by various strains of $M$. purpureus in submerged culture is affected by medium $\mathrm{pH}$ values. As reported, media $\mathrm{pH}$ plays an important role in activating key enzymes involved in pigment production and excretion by M. pupureus CCT3802 (Orozco \& Kilikian, 2008). Besides pigment excretion by the cultures, alkaline $\mathrm{pH}$ promotes a higher stability of this colorant relative to acidic values (Fabre et al., 1993 and Carvalho et al., 2005).

Carbon plays a crucial role in cell metabolism and affect the growth of the organism, concurrently, pigment production (Chatterjee et al., 2009). In the present study, results of the effect of different carbon sources showed that maltose at a concentration of $50 \mathrm{~g} / \mathrm{L}$ was the most suitable carbon source for maximum pigment production among those tested. The majority of authors have reported that glucose is a superior substrate for pigment production by Monascus species (Ahmad et al., 2009; Mukherjee \& Singh, 2011 and Prajapati et al., 2014). Results of the effect of different nitrogen sources on pigment production showed that peptone $(2.5 \mathrm{~g} / \mathrm{L})$ was the most suitable for pigment production. The superiority of peptone over the other nitrogen sources may be explained by the entrance of nitrogen into the cells as amino acids and thus generating more stable extracellular pigment (Zhang et al., 2013 and Ahmad \& Panda, 2014).

Results of the effect of different minerals on pigment production revealed that $\mathrm{Fe}^{+2}$ was the most suitable for maximum pigment production. This was supported by Lee et al. (2001) who found that $\mathrm{Fe}^{2+}$ showed the strongest stimulatory effect on pigment production. However, some stimulatory effect was also found in $\mathrm{Mn}^{2+}$, which may be attributed to strain specificity.
Results of selection of the proper solid substrate for pigment production indicated that potato peels were the most conductive as a cheap substrate for pigment production, although maximum pigment yield was obtained on using rice. In agreement with these results, Padmavathi \& Prabhudessai (2013) reported that potato peel was recognized to be the best substrate for $M$. sanguineus. Rice and its derivatives as a solid substrate were successfully used for pigment production by many authors, rice malt (Kumar et al., 2012), rice hulls (Silveira et al., 2008), unpolished rice (Dikshit \& Tallapragada, 2011), rice based solid medium (Ahmad \& Panda, 2014).

Production of maximum pigment yield by the experimental fungal strain was achieved using potato peel as a solid substrate incubated for 16 days. In literature, the optimum incubation time for maximum pigment production vary from strain to another. Ahmad \& Panda (2014) used 14 days of incubation for pigment production. Shorter incubation period (7 days) was reported for pigment production by some authors (Babitha et al., 2006 and Rajeswari et al., 2014). Maximum pigment production by the experimental fungal strain was achieved on using potato peel with a moisture content of $75 \%$. In partial accordance with these results, Ahmad \& Panda (2014) used rice based medium with a moisture content of $70 \%$. Some authors used $56-60 \%$ moisture content for maximum pigment production (Dikshit \& Tallapragada, 2012 and Padmavathi \& Prabhudessai, 2013).

Low moisture content reduces the solubility of nutrients provided to the organism by solid substrate, a lower degree of swelling and higher water tension, hence a less metabolic activity resulted (Xavier \& Lonsane, 1992). At higher moisture content, increased inhibitory effect on growth was obtained, considered to be due to substrate particle agglomeration, lower $\mathrm{O}_{2}$ transfer, decreasing the porosity and enhancement of bacterial growth (Kashyap et al., 2002). Among the moistening agents tested, optimized broth was the best for maximum pigment yield.

Rashmi \& Padmavathi (2013) reported that addition of external nitrogenous compounds showed a positive impact on pigment production. Wong \& Koehler (1983) further indicated that pigment production are influenced by the amount of carbon and nitrogen in the media. In the present 
study mineral salt solution and distilled water were used successfully for pigment production. In the same connection, Velmurugan et al. (2011) used mineral salt solution of the same composition for maximum pigment production. The use of distilled water as a moistening agent for pigment production was reported by many authors (Dikshit \& Tallapragada, 2012 and Padmavathi \& Prabhudessai, 2013). It is concluded that the production of red pigment by the solid substrate may need enrichments with nutrients, which have an essential role in promoting greater yield of pigment. Similarly, production of red and yellow pigments by Monascus purpureus was reported during cultivation of the fungus in wet bagasse containing PGY medium with corn oil in solid state for fermentation (Chiu \& Chan, 1992).

Improvement of microbial strains for the over production and improvement of industrial products has been the hallmark of all commercial fermentation processes. Such improved strains can reduce the cost of the processes with increased productivity and may also possess some specialized desirable characteristics (Parekh et al., 2000). In the present study, gamma radiation at $1 \mathrm{KGy}$ was found to be the most effective dose, and significant differences in pigment yield from the fungal strain were found at this dose. In this respect, Chen \& $\mathrm{Hu}$ (2005) were used UV and ${ }^{60} \mathrm{Co}$ gamma irradiation to develop a mutant strain of Monascus sp able to produce pigment with high concentration of mevinolin. Irradiation by gamma rays may cause some mutations to the gene of cells through the DNA repair mechanism within cells (Thacker, 1999).

The present study was extended to assess the antifungal activity of red pigment produced by the experimental fungal strain against some plant pathogens. The results indicate the activity of the pigment against Aspergillus niger, Aspergillus flavus and Alternaria sp. Although, there were no recorded activity against Fusarium solani and Penicillium sp. Ungureanu \& Ferdes (2010) reported that red pigment showed antifungal activity against some fungal strain such as Fusarium oxysporum, Fusarium roseum, Mucor, Aspergillus ochraceus, Aspergillus oryzae and Penicillium roqueforti. This suggests the red pigment of Monascus purpureus has a preservative value. They further attributed this activity to the presentence of monascidin A. Cheng et al. (2011) reported the antifungal activity of the pigment obtained from $M$. purpureus BCRC38038 culture against $C$. albicans BCRC21538 and S. cerevisiae BCRC 20822.

\section{Conclusion}

Solid state fermentation is more advantageous and superior to submerged fermentation. The obtained yield of red pigment from solid state fermentation (6.080.D/g dry substrate) was more greater than that achieved using submerged fermentation $(0.4490 . \mathrm{D} / \mathrm{ml})$. Solid fermentation yielded greater amount of pigment compared to submerged fermentation, this could be attributed to the substrates used in solid state fermentation, which supply the basic nutrients for fungi and serve as an anchor for the cells.

Acknowledgment: We are thankful to Dr. ElSayed R. El-Sayed, M.Sc., Plant Research Dept., Nuclear Research Center, Atomic Energy Authority of Egypt, Cairo, Egypt, for his sincere help and critical comments.

\section{$\underline{\text { References }}$}

Ahmad, M. and Panda, B.P. (2014) Optimization of red pigment production by Monascus purpureus MTCC 369 under solid-state fermentation using response surface methodology. Songklanakarin Journal of Science and Technology, 36, 439-444.

Ahmad, M., Nomani, S. and Panda, B. (2009) Screening of nutrient parameters for red pigment production by Monascus purpureus MTCC369 under submerged fermentation using PlackettBurman design. Chiang Mai Journal of Science, 36, 104-109.

Atlas, R.M. (2004) "Handbook of Microbiological Media", $3^{\text {rd }}$ ed., CRC Press.

Babitha, S., Soccol, C.R. and Pandey, A. (2006) Jackfruit Seed - a novel substrate for the production of Monascus pigments through solid-state fermentation. Food Technology and Biotechnology, 44, 465-471.

Babitha, S., Soccol, C.R. and Pandey, A. (2007) Solidstate fermentation for the production of Monascus pigments from jackfruit seed. Bioresources of Technology, 98, 1554-1560.

Blanc, P.J., Laussac, J.P., Bars, J.Le, Bars, P.Le, Lorret, M.O., Pareilleu, A., Prome, D., Prome, 
J.C., Santene, A.L. and Goma, G. (1995) Characterization of Monascidin-a from Monascus as citrinin, International Journal of Food Microbiology, 27, 201-213.

Bennett, J.V., Brodie, J.L., Benner, E.J. and Kirby, W.M.M. (1996) Simplified, accurate method for antibiotic assay of clinical specimens. Applied Microbiology, 14, 170-177.

Chatterjee, S., Maity, S., Chattopadhyay, P., Sarkar, A., Laskar, S. and Sen, S.K. (2009) Characterization of red pigment from Monascus in submerged culture red pigment from Monascus purpureus. Journal of Applied Sciences Research, 5, 2102-2108.

Carvalho, J.C., Pandey, A., Babitha, S. and Soccol, C.R. (2003) Production of Monascus biopigmentation: An overview. Agro. Food Industry Hi Tech. 14, 619-624.

Chen, F. and Hu, X. (2005) Study on red fermented rice with high concentration of monacolin $\mathrm{K}$ and low concentration of citrinin. International Journal of Food Microbiology, 103, 331-337.

Campoy, S., Rumbero, A. and Martin, J.F. (2006) Characterization of an hyperpigmenting mutant of Monascus purpureus IB1: Identification of two novel pigment chemical structures. Applied Microbiology and Biotechnology, 70, 488-96.

Cheng, M.J., Wua, M.D., Chen, I.S., Tseng, M. and Yuan, G.F. (2011) Chemical constituents from the fungus Monascus purpureus and their antifungal activity. Phytochemistry Letters, 4, 372-376.

Chaerani, R. and Voorrips, R.E. (2006) Tomato early blight (Alternaria solani): The pathogen, genetics, and breeding for resistance. Journal of General Plant Pathology, 72, 335-347.

Carvalho, J.C., Oishi, B.O., Pandey, A. and Soccol, C.R. (2005) Biopigments from Monascus: Strains selection, citrinin production and color stability. Brazilian Achieves of Biology and Technology, 48, 885-894.

Chiu, S.W. and Chan, S.M. (1992) Production of pigments by Monascus purpureus using sugarcane bagasse in roller bottle cultures. World Journal of Microbiology and Biotechnology, 8, 68-70.

Dikshit, R. and Tallapragada, P. (2011) Monascus purpureus: A potential source for natural pigment production. Journal of Microbiology and Biotechnology Research, 1, 164-174.

Dikshit, R. and Tallapragada, P. (2012) Comparative study of Monascus sanguineus and Monascus purpureus as potential sources for red pigment production. International Journal of Pharma and Bio Sciences, 3(B), 885-895

Fabre, C.E., Santerre, A.L., Loret, M.D., Baberian, R., Parailleux, A. and Goma, G. (1993) Production and food application of the red pigments of Monascus ruber. Journal of Food Sciences, 58, 1099-103.

Hamdi, M., Blanc, P.J. and Goma, G. (1996) Effect of aeration conditions on the production of red pigments by Monascus purpureus growth on prickly pear juice. Process Biochemistry, 31, 543547.

Joshi, V.K., Attri, D. Anjubala and Bhushan, S. (2003) Microbial pigments. Indian Journal of Biotechnology, 2, 362-369.

Kumar, A., Verma, U. and Sharma, H. (2012) Antibacterial activity Monoascus purpureus (red pigment) isolated from rice malt. Asian Journal of Biological and Life Science, 1, 252-255.

Kashyap, P., Sabu, A., Pandey, A. and Szakacs, G. (2002) Extra-cellular L-glutaminase production by Zygosaccharomyces rouxii under solid state fermentation. Process Biochemistry, 38, 307-312.

Lee, B., Park, N., Piao, H.Y. and Chung, W. (2001) Production of red pigments by Monascus purpureus in submerged culture. Biotechnology Bioprocess Engineering, 6, 341-346.

Lin, Y.L., Wang, T.H., Lee, M.H. and Su, N.W. (2008) Biologically active components and nutraceuticals in the Monascus-fermented rice: A review. Applied Microbiology and Biotechnology, 77, 965-973.

Leslie, J., Summerell, F. and Brett, A. (2006) "The Fusarium Laboratory Manual". Ames: Blackwell. pp. 250-254. ISBN 0813819199.

Louw, J.P. and Korsten, L. (2015) Pathogenicity and host susceptibility of Penicillium spp. on citrus. The American Phytopathological Society, 99, 21-30.

Mukherjee, G. and Singh, S.K. (2011) Purification 
and characterization of a new red pigment from Monascus purpureus in submerged fermentation. Journal of Process Biochemistry, 46, 188-192.

Nelson, P.E., Toussoun, T.A. and Marasas, W.F.O. (1983) "Fusarium species: An Illustrated Manual for Identification". Pennsylvania State University Press, University Park. pp. 193.

Orozco, S.F.B. and Kiliki, B.V. (2008) Effect of $\mathrm{pH}$ on citrinin and red pigments production by Monascus purpureus CCT3802. World Journal of Microbiology and Biotechnology, 24, 263-268.

Patcharee, P., Pinthong, R., Aphirak, P. and Noppol, E. (2007) Review of Angkak production (Monascus purpureus). Chiang Mai Journal of Sciences, 34, 319-328.

Panesar, R., Kaur, S. and Panesar, P.S. (2015)Production of microbial pigments utilizing agro-industrial waste: A review. Journal of Food Science, 1, 70-76.

Parekh, S., Vinci, V.A. and Strobel, R.J. (2000) Improvement of microbial strains and fermentation processes. Applied Microbiology and Biotechnology, 54, 287-301.

Padmavathi, T. and Prabhudessai, T. (2013) A solid liquid state culture method to stimulate Monascus pigments by intervention of different substrates. International Research Journal of Biological Sciences, 2, 22-29.

Prajapati, V.P., Soni, N., Trivedi, U.B. and Patel, K.C. (2014) An enhancement of red pigment production by submerged culture of Monascus purpureus MTCC 410 employing statistical methodology. Biocatalysis and Agricultural Biotechnology, 3, 140-145.

Rashmi, D. and Padmavathi, T. (2013) Exploring Monascus sanguineus as a potential natural source for pigment production. International Research Journal of Biological Sciences, 2, 59-67.

Rajeswari, T.R., Ponnusami, V. and Sugumaran, K.R. (2014) Production of Monascus pigment in low cost fermentation. International Journal of ChemTech Research, 6, 2929-2932.

Ramirez-Camejo, L.A., Zuluaga-Montero, M.A., Lazaro-Escudero, M.A., Hernandez-Kendall, V.N. and Bayman, P. (2012) Phylogeography of the cosmopolitan fungus Aspergillus flavus: Is everything everywhere?. Fungal Biology, 116, $452-$ 463.

Silveira, S.T., Daroit, D.J. and Brandelli, A. (2008) Pigment production by Monascus purpureus in grape waste using factorial design. LWT: Food Sciences and Technology, 41, 170-174.

Singh, N., Goel, G., Singh, N. and Pathak, B.K. (2015) Modeling the red pigment production by Monascus purpureus MTCC 369 by Artificial Neural Network using rice water based medium. Journal of Food Bioscience, 11, 17-22.

Sharma, R. (2012) Pathogenicity of Aspergillus nigar in plants. Cibtech Journal of Microbiology.

Tallapragada, P., Dikshit, R. and Dessai, P.T. (2013) Effect of glycerol as a sole carbon source on Monascus sp. for pigment production. International Food Research Journal, 20, 3265-3268.

Thacker, J. (1999) Repair of ionizing radiation damage in mammalian cells. Alternative pathways and their fidelity. CR Academy of Science III, 322, 103-108.

Ungureanu, C. and Ferdes, F. (2010) Antibacterial and antifungal activities of red rice obtained from Monascus purpureus. Chemical Engineering Transaction, 20, 223-228.

Velmurugan, P., Hur, H., Balachandar, V., KamalaKannan, S., Kui-Jae Lee, K.J., Lee, S.M., Chae, J.C., Shea, P.J. and Oh, B.T. (2011) Monascus pigment production by solid-state fermentation with corn cob substrate. Journal of Biosciences and Bioengineering, 112, 590-594.

Wong, H. and Koehler, P.E. (1983) Production of red water-soluble Monascus pigments. Journal of Food Sciences, 48, 1200-1203.

Xavier, S. and Lonsane, B.K. (1992) Relevance of solid state fermentation for biodegradation of carbohydrates in sugar-cane pressmud and stillage. In: Abstracts, National Meet of Food Scientists and Technologists on Food Science and Technology Development in the Third World and Curriculum Development. April 10, Association of Food Scientists and Technologists, Mysore, India, p 58.

Zhou, B., Wang, J., Pu, Y., Zhu, M., Liu, S. and Liang, S. (2009) Optimization of culture medium 
for yellow pigments production with Monascus anka mutant using response surface methodology. European Food Research of Technology, 228, 895901.

Zhang, Y.L., Kong, L.C., Yin, C.P., Jiang, D.H., Jiang, J.Q., He, J. and Xiao, W.X. (2013) Extraction optimization by response surface methodology, purification and principal antioxidant metabolites of red pigments extracted from bayberry (Myrica rubra) pomace. LWT: Food Science and Technology, 51, 343-347.

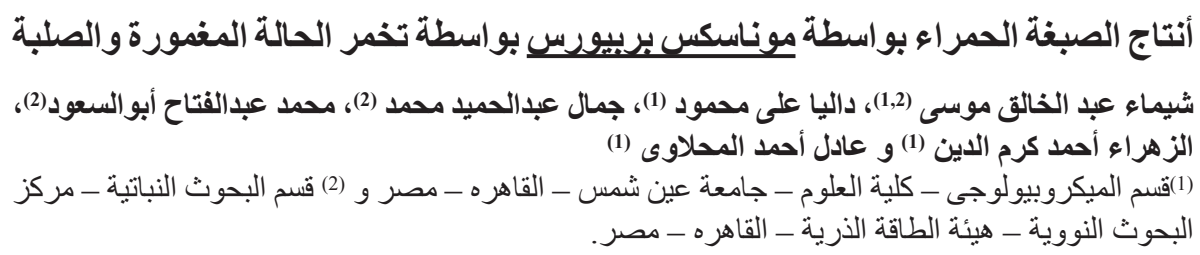

نظرا للتطبيقات الصناعية الواسعة اتجهت هذه الدراسة لأنتاج الصبغة الحمراء بواسطة فطره الموناسكس

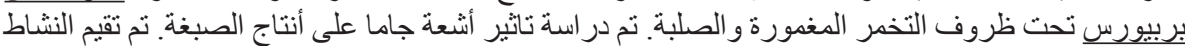

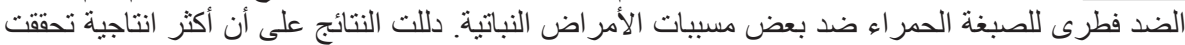

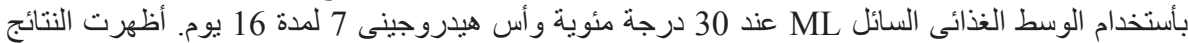

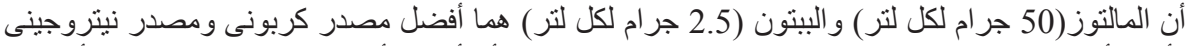

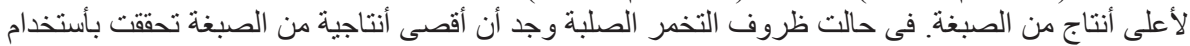

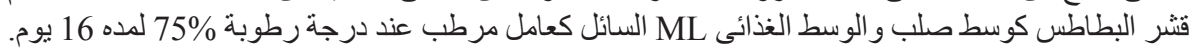

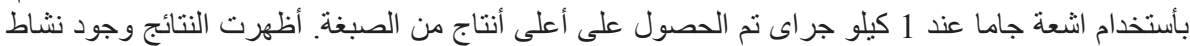

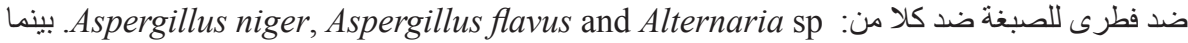

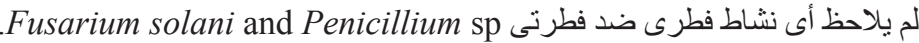

